\title{
Chemical Constituents of the Essential Oil of Invasive Chromolaena odorata leaves in Central Nepal
}

\author{
Lal B Thapa ${ }^{1}$, Khadka Bahadur Pal ${ }^{* 2}$, Tayer Mohamad Miya ${ }^{3}$, Tej Bahadur Darji', \\ Seeta Pathak ${ }^{1}$, Gunanand Pant ${ }^{4}$, Ramesh Raj Pant ${ }^{5}$ \\ ${ }^{1}$ Central Department of Botany, Tribhuvan University, Kirtipur, Kathmandu, Nepal \\ ${ }^{2}$ Tri-Chandra Multiple Campus, Tribhuvan University, Kathmandu, Nepal \\ ${ }^{3}$ Department of Food Technology and Quality Control, Government of Nepal, Kathmandu, Nepal \\ ${ }^{4}$ Department of Biology, Kailali Multiple Campus, Tribhuvan University, Kailali, Nepal \\ ${ }^{5}$ Central Department of Environmental Sciences, Tribhuvan University, Kirtipur, Kathmandu, Nepal \\ *Corresponding E-mail: khadka.pal@gmail.com \\ (Received: September 30, 2020; Revised: January 8, 2021; \& Accepted: January 8, 2021)
}

\begin{abstract}
Chromolaena odorata is one of the widely distributed invasive alien plants in the tropical to subtropical regions of Nepal. It has the ability to impact native species in its invaded range by multiple modes such as allelopathy including volatilization. This study aims to identify volatile chemical components in the essential oil of $C$. odorata. The leaf samples of $C$. odorata were collected from the Radha Krishna Community Forest, Chitwan district of Nepal. The essential oil from the leaves was extracted and the chemical composition of the oil was analyzed by gas chromatography (GC) and GC-mass spectrometry (GC-MS). A total of 19 chemical components from the oil were identified. The major components were linalool $(21.64 \%)$; $\beta$-pinene $(9.43 \%)$; 1,3-cycloheptadiene (8.92\%); $\beta$-cubebene (7\%); cinnamaldehyde $(5.30 \%)$ and caryophyllene oxide $(4.94 \%)$. To the best of our knowledge, the presence of o-methoxy cinnamaldehyde and isoeugenyl acetate was not listed as the chemical constituents in volatile oils of $C$. odorata previously. The components of the volatile oil are suspected to have an allelopathic effect on native species, anti-herbivory properties, and medicinal values. Therefore, this study could be important to understand plant invasiveness and utilization of the plant for the extraction of bioactive compounds that could contribute to control and manage the invasive plants in the invaded areas.
\end{abstract}

Keywords: Invasive plant, Siam weed, essential oil, GC-MS analysis, phytotoxicity, allelopathy

\section{Introduction}

Chromolaena odorata (L.). R. M. King and H. Rob. (syn. Eupatorium odoratum L.), Siam weed, is a highly problematic invasive alien plant species in Nepal. It is native to tropical America and Mexico, and currently, it has been naturalized in many countries of the world including Nepal [1]. It is one of the rapidly growing perennial shrubs of the family Asteraceae. This species is one among 100 of the world's worst invasive alien species [2]. It is distributed from tropical to sub-tropical regions $(75 \mathrm{~m}-1700 \mathrm{~m})$ of eastern to western Nepal [3]. Massive colonization of C. odorata is found in forest margins, fallow lands, roadsides, and even in the agro-ecosystems [3-6]. As one of the troublesome, aggressive, and noxious weeds, it has threatened native biodiversity, impacted peoples' livelihood and economy [3-5].
Chromolaena odorata produces many allelochemicals such as terpenoids, phenolics, and alkaloids from its underground and aerial parts $[7,8]$. The allelochemicals produced by this plant are known to be toxic for seed germination, growth, and development of native plant species [9]. The allelochemicals are also toxic to livestock [10]. The chemical constituents of its volatile oil such as terpenoids are known as the harmful allelochemicals [11]. These chemicals are one of the mechanisms of harming native species, as a result, the invasive species grow faster in their novel range [12]. Medicinally, the plant oil has the potential to remedy diseases such as treatment of malaria, wounds, stomach disorders, skin diseases, coughs, and colds, etc. [13]. Besides, the essential oil of this species is insecticidal [14], used as an insect repellent [15], and antibacterial $[16,17]$. Therefore, the volatile 
components of this species have an important role in plant invasiveness, toxicity, and medicine.

A survey of the literature revealed that the essential oil of C. odorata contains several volatile chemicals and other biologically active constituents [18-21]. Documentation of chemical constituents of $C$. odorata volatile oil has been carried out from different countries such as Nigeria [19], Thailand [20], Malaysia [21], Vietnam [22], Ivory Coast [23], Benin [24], and Ghana [25], etc. Such documentation from Nepal is very meager. It is an urgent task to know the chemical constituents of such invasive plants in Nepal to understand whether the constituents vary with geographical regions. Hence, this study aims to document the chemical components in the volatile oil of $C$. odorata leaves from the Tarai region of central Nepal.

\section{Materials and Methods Collection of plant materials}

Fresh leaves of $C$. odorata were collected from the invaded site of the Radha Krishna Community Forest $\left(27^{\circ} 34^{\prime} 59.99^{\prime \prime} \mathrm{N}\right.$ and $84^{\circ} 30^{\prime}$ 59.99"E, 127 masl) located at Meghauli-26, south-western part of Bharatpur Metropolitan City, Chitwan, Nepal in July 2019. The samples were stored in the refrigerator $\left(4^{\circ} \mathrm{C}\right)$. The voucher specimen has been deposited at the Tribhuvan University Central Herbarium (TUCH), Central Department of Botany, Tribhuvan University, Kirtipur, Kathmandu, Nepal.

\section{Extraction of essential oil and chemical analysis}

The essential oil from the collected leaf sample was extracted by using Clevenger apparatus (300 $\mathrm{ml}$ ) for about 3 hours at $80^{\circ} \mathrm{C}$ by the process of hydro-distillation at Central Department of Botany, Tribhuvan University, Kirtipur, Kathmandu, Nepal.



Figure 1: Chromolaena odorata plant photograph
The light yellow colored extracted oil was collected and transferred to a clean glass vial, sealed, and stored at a low temperature $\left(0-4^{\circ} \mathrm{C}\right)$ until further analyses.

The components of the essential oil were separated by Gas Chromatography (GC) and identified by Mass Spectrometry (MS). The GC-MS analysis was carried out at the Department of Food Technology and Quality Control, Government of Nepal, Babarmahal, Kathmandu, Nepal. The Shimadzu QP2010 Plus operating system in electron impact (EI) mode was used for GC-MS analysis. The essential oil was subjected to a gas chromatograph fitted with an Rtx5MS column $(30 \mathrm{~m} \times 0.25 \mathrm{~mm}$ i.d., film thickness 0.25 $\mu \mathrm{m})$, coupled to a QP2010 Plus mass detector. The column oven temperature was kept at $80^{\circ} \mathrm{C}$ for 2.0 minutes then gradually raised to $280^{\circ} \mathrm{C}$ at a rate of $6^{\circ} \mathrm{C} / \mathrm{min}$ and finally held isothermally for 5 minutes. The injector temperature was set at $220^{\circ} \mathrm{C}$. Helium was used as a carrier gas at a total flow rate of $18.5 \mathrm{~mL} /$ min. One microliter of the diluted oil samples $(1 / 100$ in ethanol, $v / v$ ) were injected manually (split mode, split ratio $1: 15$ ) with $1.03 \mathrm{~mL} / \mathrm{min}$ through the column. For GC-MS detection, an electron ionization system with ionization energy of $70 \mathrm{eV}$ on an Rtx-5MS mass spectrometer connected to GC-MS solution software was used. Spectra were obtained over the mass range of 40 to $500 \mathrm{~m} / \mathrm{z}$ at scan speed 1000 millisecond. The relative percentage composition of individual component was calculated from the GC peak area of all the components of the chromatograph.

\section{Qualitative and quantitative analysis}

The relative quantity of the chemical components present in the extracts of $C$. odorata was expressed as a percentage based on the peak area produced in the chromatogram. The identification of compounds was accompanied by comparing with the National Institute of Standards and Technology (NIST 05S) library. The quantification of the compounds was determined by the relative percentage area of the peaks.

\section{Results and Discussion}

A total of 19 components were identified from the oil of $C$. odorata. The list of the components, $\mathrm{R}$ time, area $\%$, and base $\mathrm{m} / \mathrm{z}$ ratio have been given in Table 1 and the total ion chromatogram (TIC) is given in Figure 2. Three components, linalool (21.64\%), $\beta$-Pinene (9.43\%), and 1, 3-cycloheptadiene (8.92\%) were the major compounds having a high percentage comparing to other components in the oil. Other compounds $\beta$-cubebene, cinnamaldehyde, and 
caryophyllene oxide occupied about 4 to $7 \%$ (Table $1)$. Rest, caryophyllene, cinnamyl acetate, $\beta$-ocimene, D-limonene, o-methoxy cinnamaldehyde, bornyl acetate, $\delta$-cadinene, isoeugenyl acetate, humulene, cadinol, terpinen-4-ol, and p-cymene were the compounds having low concentrations i.e. $<4 \%$ (Table 1).

Table 1: The list of components, $R$ time, area $\%$, and base

\begin{tabular}{|c|c|c|c|}
\hline Compounds & R Time & Area $\%$ & Base $\mathbf{m} / \mathbf{z}$ \\
\hline$\beta$-Pinene & 4.356 & 9.43 & 93.10 \\
\hline p-Cymene & 5.139 & 1.18 & 119.10 \\
\hline D-Limonene & 5.213 & 2.57 & 68.05 \\
\hline$\beta$-Ocimene & 5.518 & 3.04 & 93.10 \\
\hline Linalool & 6.62 & 21.64 & 71.05 \\
\hline Terpinen-4-ol & 8.327 & 1.37 & 71.10 \\
\hline Cinnamaldehyde & 10.402 & 5.30 & 131.10 \\
\hline Bornyl acetate & 10.7 & 1.77 & 95.10 \\
\hline 1,3-Cycloheptadiene & 10.855 & 8.92 & 79.05 \\
\hline Copaene & 12.65 & 0.63 & 105.10 \\
\hline Caryophyllene & 13.611 & 3.66 & 69.10 \\
\hline Cinnamyl acetate & 14.074 & 3.22 & 43.05 \\
\hline Humulene & 14.32 & 1.53 & 93.10 \\
\hline$\beta$-Cubebene & 14.892 & 7.00 & 161.10 \\
\hline$\delta$-Cadinene & 15.69 & 1.75 & 161.10 \\
\hline o-Methoxycinnamaldehyde & 15.865 & 2.50 & 131.10 \\
\hline Caryophyllene oxide & 16.966 & 4.94 & 79.05 \\
\hline Cadinol & 17.896 & 1.50 & 119.10 \\
\hline Isoeugenyl acetate & 18.507 & 1.66 & 163.05 \\
\hline
\end{tabular}

Comparing to the prior literature, the types and concentrations of chemical components in present study are distinct. Ling et al., (2003) had found trans-caryophyllene $(16.58 \%), \delta$-cadinene $(15.85 \%)$, $\alpha$-copaene $(11.58 \%)$, caryophyllene oxide $(9.63 \%)$, germacrene-D $(4.96 \%)$, and $\delta$-humulene $(4.32 \%)$ as the major compounds in C.odorata essential oil [11]. Similarly, Owolabi et al. (2010) had identified $\alpha$-pinene $(42.2 \%), \beta$-pinene $(10.6 \%)$, germacrene D (9.7\%), $\beta$-copaen-4 $\alpha$-ol (9.4\%), (E)-caryophyllene $(5.4 \%)$, and geijerene/pregeijerene (7.5\%) as the major components [19]. The major components identified by Pisutthanan et al., (2006) were pregeijerene $(17.6 \%)$, germacrene D $(11.1 \%)$, $\alpha$-pinene $(8.4 \%)$, $\beta$-caryophyllene $(7.3 \%)$, vestitenone $(6.5 \%), \beta$-pinene $(5.6 \%), \delta$-cadinene $(4.9 \%)$, geijerene $(3.1 \%)$, bulnesol $(2.9 \%)$, and trans-ocimene (2.2\%) [20].

The major components identified by Félicien et al.

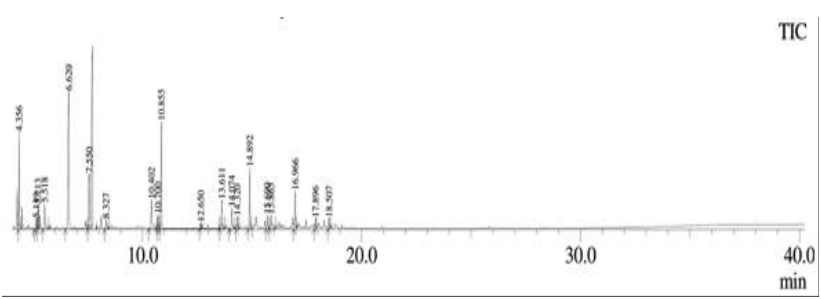

Figure 2: Total ion chromatogram (TIC) of volatile oil of C. odorata

(2012) were similar to the findings of Pisutthanan et al. (2006) but there was variation in concentrations of the components $[20,26]$. Contrasting to these literature, Joshi (2013) had reported himachalol (24.2\%), 7-isopropyl-1,4-dimethyl-2-azulenol (17.6\%), and 2-methoxy-6-(1-methoxy-2-propenyl) naphthalene $(5.6 \%)$ as the major compounds from $C$. odorata in India [18]. The major components identified in our study were linalool (21.64\%), $\beta$-pinene $(9.43 \%)$, and 1,3 -cycloheptadiene $(8.92 \%)$ which were quite different than the findings of others. Interestingly, the present study indicates that the types and amount of major components in the volatile oil vary with geographical locations.

The compounds such as $\beta$-pinene, copaene, $\delta$-cadinene, caryophyllene, caryophyllene oxide, humulene, and ocimene identified from our study were common with the findings of previous studies [19,20,24$26]$ but the presence of o-methoxy cinnamaldehyde and isoeugenyl acetate were not listed as the chemical constituents in essential oils of $C$. odorata in aforementioned studies. The mass spectra and chemical structure of o-methoxy cinnamaldehyde and isoeugenyl acetate are given in Figure 3 . Thus, these two compounds should be further confirmed as the new report from the $\mathrm{C}$. odorata collected from Tarai region of central Nepal.

As $C$. odorata has negative effects on native plant species, forage for livestock, crops, soil and soil microbes, it is one of the worst invasive plants $[4,27,28]$. And, allelopathy is one of the important mechanisms of the plant to affect negatively other species [31]. Previous studies have confirmed that the allelochemicals present in aerial and underground parts of $C$. odorata are phytotoxic to other plants [7,29]. Certain allelochemicals (components of volatile oils) such as cadinene, caryophyllene, pinene, limonene, etc. are found to be phytotoxic compounds [30-32]. Therefore, the presence of these compounds in this invasive weed might have harmed the Nepalese native plants in its invaded range.

On the other hand, the compounds such as $\beta$-pinene, $\beta$-cubebene, $\beta$-ocimene, and linalool are the volatile terpenes released in response to herbivory by several 

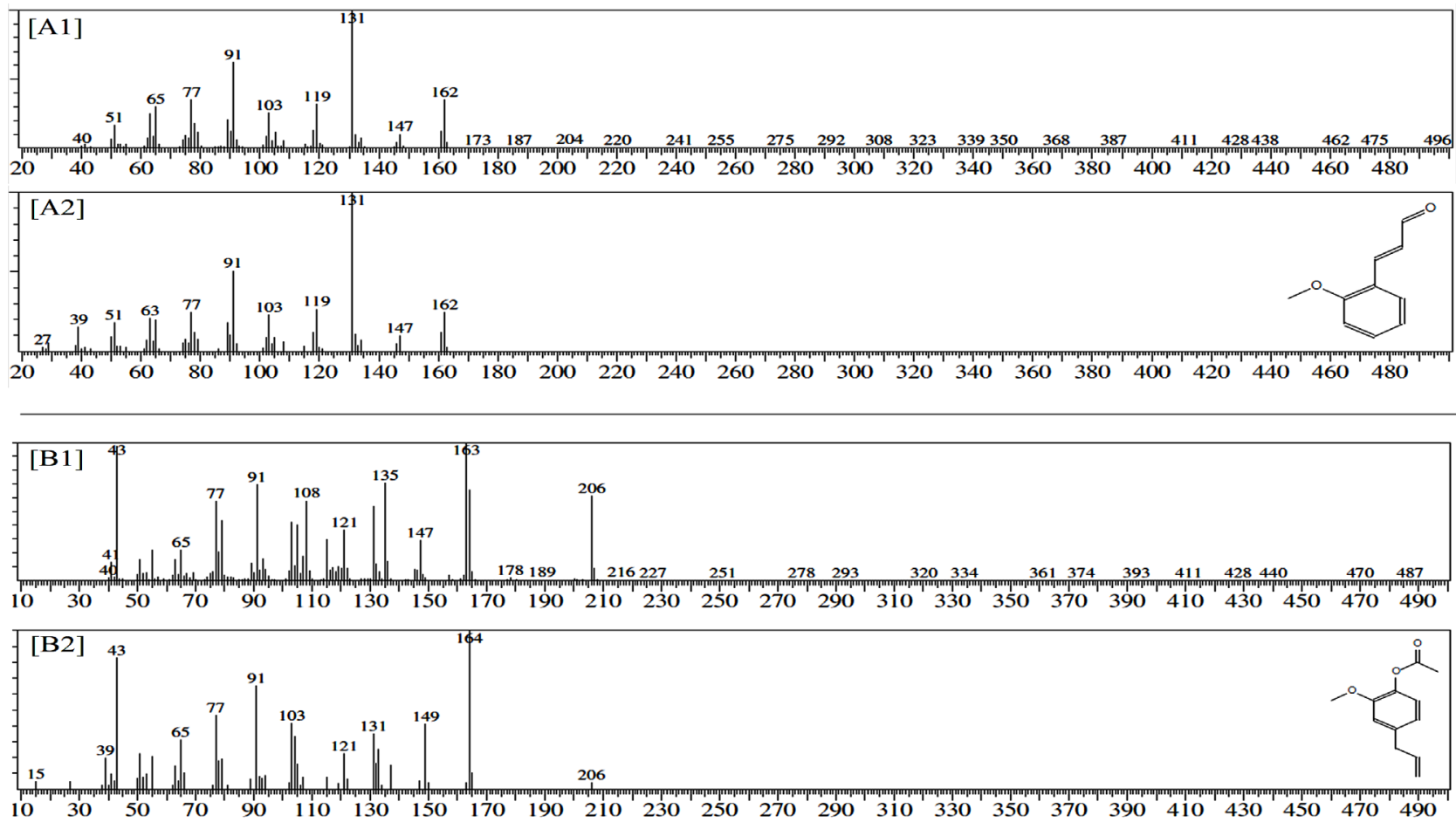

Figure 3 Mass spectra of o-methoxy cinnamaldehyde [A1] and isoeugenyl acetate [B1] obtained from the volatile oil of C. odorata and the spectra of same compounds obtained from NIST library [A2 and B2]

plants [33-35]. As these compounds are found in the leaves of $C$. odorata, it is expected that these defensive chemicals are used by this plant against herbivory damage. Meanwhile, less damage by herbivores to invasive plants is considered as one of the mechanisms for successful growth in a novel range [36,37]. Hence, the abundance of anti-herbivory chemicals in $C$. odorata is one of the causes of successful growth in the native environment. Therefore, exploration of such allelochemicals would have great significance to understand the plant invasiveness as well as their potential impacts on the native environment.

Moreover, control and management of the naturalized $C$. odorata have become a challenging issue throughout the world. It is often suggested that the utilization of such invasive plants can be one way to manage and control them sustainably. Several studies show that $C$. odorata is used as a medicinal plant as it has many ethnopharmacological uses, for example, treatment of malaria, wounds, stomach disorders, skin diseases, coughs, and colds, etc. [13]. There might be a great role of several compounds present in C. odorata for the treatments of such diseases. As an example, linalool is anti-inflammatory, anticancer, antihyperlipidemic, antimicrobial, analgesic, anxiolytic, antidepressive, and neuroprotective properties [38]. Hence, C. odorata can be utilized for the extraction of such high valuable medicinal compounds.

\section{Conclusion}

The present study identified 19 chemical compounds from the essential oil of $C$. odorata leaves collected from the Radha Krishna Community Forest of Meghauli, Chitwan, Nepal. The major compounds were linalool; $\beta$-pinene; 1,3-cycloheptadiene; $\beta$-cubebene; cinnamaldehyde, and caryophyllene oxide. The study indicates that the types and amount of major components in the volatile oil vary with geographical locations. Importantly, the presence of o-methoxy cinnamaldehyde and isoeugenyl acetate in this study may be the new report from the $C$. odorata. Most of the components of the volatile oil identified are allelochemicals, anti-herbivory, and medicinal. Utilization of $C$. odorata for the extraction of bioactive compounds can contribute to the control and management of this plant in Nepal.

\section{Acknowledgments}

The authors are thankful to the Central Department of Botany, Tribhuvan University, and Department of Food Technology and Quality Control, Government of Nepal for GC-MS analysis for providing the research facilities. University Grants Commission, Nepal is highly acknowledged for funding. We express our gratitude to Prof. Emeritus Dr. Pramod Kumar Jha and Prof. Dr. Ram Kailash Prasad Yadav for every support and encouragement. 


\section{References}

1. R. M. King, and H. Robinson, Studies in the Eupatorieae (Compositae). XXIV. The genus Chromolaena, Phytologia, 1970, 20, 196-209.

2. S. Lowe, M. Browne, S. Boudjelas, and M. De Poorter, 100 of the world's worst invasive alien species: a selection from the global invasive species database, The Invasive Species Specialist Group (ISSG) a specialist group of the species survival commission (SSC) of the World Conservation Union (IUCN), 2000, p. 12.

3. S. Tiwari, B. Adhikari, M. Siwakoti, and K. Subedi, An inventory and assessment invasive alien plant species of Nepal, IUCN-The World Conservation Union Nepal, 2005, pp viii+114.

4. L. B. Thapa, K. Kaewchumnong, A. Sinkkonen, and K. Sridith, Impacts of invasive Chromolaena odorata on species richness, composition and seedling recruitment of Shorea robusta in a tropical Sal forest, Nepal, Songklanakarin Journal of Science and Technology, 2016, 38(6), 683-689.

5. B. B. Shrestha, U. B. Shrestha, K. P. Sharma, R. B. Thapa-Parajuli, A. Devkota, and M. Siwakoti, Community perception and prioritization of invasive alien plants in Chitwan-Annapurna Landscape, Nepal, Journal of Environmental Management, 2019, 229, 38-47.

6. B. B. Shrestha, Invasive alien plant species in Nepal, In: Frontiers of Botany, Eds. by P. K. Jha, M. Siwakoti, and S. Rajbhandary, Central Department of Botany, Tribhuvan University, Kirtipur, Kathmandu Nepal, 2016, pp 269-284.

7. S. R. Ambika, and S. Poornima, Allelochemicals from Chromolaenaodorata (L.)King and Robinson for increasing crop productivity, Chromolaena in the Asia-Pacific region, Proceedings of the $6^{\text {th }}$ international workshop on biological control and management of Chromolaena held in Cairns, Australia, May 6-9, 2003, Eds. by M. D. Day, and R. E. McFadyen, Australian Centre for International Agricultural Research, Canberra, 2004, pp. 19-24.

8. R. S. Tripathi, A. S. Yadav, and S. P. S. Kushwaha, Biology of Chromolaena odorata, Ageratina adenophora and Ageratina riparia: A review, Invasive alien plants: an ecological appraisal for the Indian subcontinent, Eds. by J. R. Bhatt, J. S. Singh, S. P. Singh, R. S. Tripathi and R. K. Kohli, CAB International, Cambridge, 2012, pp. 43-56.

9. R. S. Tripathi, R. S. Singh, and J. N. P. Rai, Allelopathic potential of Eupatoriumadenophorum -a dominant ruderal weed of Meghalaya, Proceedings of Indian National Science Academy, Part B, Biological Science, 1981, 47: 458-465.

10. A. Biller, M. Boppré, L. Witte, and T. Hartmann, Pyrrolizidine alkaloids in Chromolaena odorata,
Chemical and chemoecological aspects, Phytochemistry, 1994, 35(3), 615-619.

11. B. Ling, M. Zhang, C. Kong, X. Pang, and G. Liang, Chemical composition of volatile oil from Chromolaena odorata and its effect on plant, fungi and insect growth, Chinese Journal of Applied Ecology, 2003, 14(5), 744-746.

12. J. L. Hierro, and R. M. Callaway, Allelopathy and exotic plant invasion, Plant and Soil, 2003, 256(1), 29-39.

13. A. G. Omokhua, L. J. McGaw, J. F. Finnie, and J. Van Staden, Chromolaena odorata (L.) RM King \& H. Rob. (Asteraceae) in sub-Saharan Africa: A synthesis and review of its medicinal potential, Journal of Ethnopharmacology, 2016, 183, 112-122.

14. H. Bouda, L. A. Tapondjou, D. A. Fontem, and M. Y. D. Gumedzoe, Effect of essential oils from leaves of Ageratum conyzoides, Lantana camara and Chromolaena odorata on the mortality of Sitophilus zeamais (Coleoptera, Curculionidae), Journal of Stored Product Research, 2001, 37, 103-109.

15. S. Cui, S. Tan, G. Ouyang, S. Jiang, and J. Pawliszyn, Headspace solid-phase micro extraction gas chromatography-mass spectrometry analysis of Eupatorium odoratum an oviposition repellent, Journal of Chromatography B, 2009, 877(20-21), 1901-1906.

16. S. I. Inya-Agha, B. O. Oguntimein, A. Sofowora, and T. V. Benjamin, Phytochemical and antibacterial studies on the essential oil of Eupatorium odoratum, International Journal of Crude Drug Research, 1987, 25(1), 49-52.

17. D. Bamba, J. M. Bessière, C. Marion, Y. Pélissier, and I. Fouraste, Essential oil of Eupatorium odoratum, Planta Medica, 1993, 59(2), 184-185.

18. R. K. Joshi, Chemical composition of the essential oil of Chromolaena odorata (L.) RM King \& H. Rob. roots from India, Journal of Chemistry, 2013, 195057.

19. M. S. Owolabi, A. Ogundajo, K. O. Yusuf, L. Lajide, H. E. Villanueva, J. A. Tuten, and W. N. Setzer, Chemical composition and bioactivity of the essential oil of Chromolaena odorata from Nigeria, Records of Natural Products, 2010, 4(1), 72-78.

20. N. Pisutthanan, B. Liawruangrath, S. Liawruangrath, A. Baramee, A. Apisariyakul, J. Korth, and J. B. Bremner, Constituents of the essential oil from aerial parts of Chromolaena odorata from Thailand, Natural Product Research, 2006, 20(6), 636-640.

21. O. R. Alara, and N. H. Abdurahman, GC-MS and FTIR analyses of oils from Hibiscus sabdariffa, Stigma maydis and Chromolaena odorata leaf obtained from Malaysia: Potential sources of fatty acids, Chemical Data Collections, 2019, 20, 100-200.

22. N. X. Dung, L. K. Bien, and P. A. Leclercq, 
The constituents of the leaf oil of Chromolaena odorata (L.) RM King and H. Robinson from Vietnam, Journal of Essential Oil Research, 1992, 4(3), 309-310.

23. Z. F. Tonzibo, E. Wognin, J. C. Chalchat, and Y. T. N'Guessan, Chemical investigation of Chromolaena odorata L. King Robinson from Ivory Coast, Journal of Essential Oil Bearing Plants, 2007, 10(2), 94-100.

24. C. Kossouoh, M. Moudachirou, V. Adjakidje, J. C. Chalchat, G. Figuérédo, and P. Chalard, Volatile constituents of Chromolaena odorata (L.) RM King \& H. Rob. Leaves from Benin, Journal of Essential Oil Bearing Plants, 2011, 14(2), 224-228.

25. J. Osei-owusu, A. Acheampong, J. V. K. Afun, and S. O. Acquaah, Chemical composition of the headspace volatiles from Chromolaena odorata (L.) RM King in Ghana, Journal of Essential Oil Bearing Plants, 2017, 20(5), 1418-1423.

26. A. Félicien, A. G. Alain, D. T. Sébastien, T. Fidele, Y. Boniface, M. Chantal, and S. Dominique, Chemical composition and Biological activities of the Essential oil extracted from the Fresh leaves of Chromolaena odorata (L. Robinson) growing in Benin, ISCA Journal of Biological Sciences, 2012, 1(3), 7-13.

27. R. T. Shackleton, A. B. Witt, W. Nunda, and D. M. Richardson, Chromolaena odorata (Siam weed) in eastern Africa: distribution and socioecological impacts, Biological Invasions, 2017, 19(4), 1285-1298.

28. M. S. Tiébré, and Z. R. G. Gnanazan, Impact of Chromolaena odorata (L.) RM King \& H. Rob. (Asteraceae) on the floristic composition and the physico-chemical properties of the soil of a coastal relict forest, International Journal of Innovation and Applied Studies, 2018, 24(2), 773-788.

29. G. Hu, and Z. Zhang, Allelopathic effects of Chromolaena odorata on native and non-native invasive herbs, Journal of Food, Agriculture and Environment, 2013, 11(1), 878-882.

30. S. H. Eom, H. S. Yang, and L. A. Weston, An evaluation of the allelopathic potential of selected perennial groundcovers: foliar volatiles of catmint $($ Nepeta $\times$ faassenii) inhibit seedling growth, Journal of Chemical Ecology, 2006, 32(8), 1835-1848.
31. B. A. Sánchez-Muñoz, M. I. Aguilar, B. KingDíaz, J. F. Rivero, and B. Lotina-Hennsen, The sesquiterpenes $\beta$-caryophyllene and caryophyllene oxide isolated from Senecio salignus act as phytogrowth and photosynthesis inhibitors, Molecules, 2012, 17(2), 1437-1447.

32. F. Zhang, J. Guo, F. Chen, W. Liu, and F. Wan, Identification of volatile compounds released by leaves of the invasive plant croftonweed (Ageratina adenophora, Compositae), and their inhibition of rice seedling growth, Weed Science, 2012, 60(2), 205-211.

33. H. Danner, G. A. Boeckler, S. Irmisch, J. S. Yuan, F. Chen, J. Gershenzon, S. B. Unsicker, and T. G. Köllner, Four terpene synthases produce major compounds of the gypsy moth feedinginduced volatile blend of Populus trichocarpa, Phytochemistry, 2011, 72(9), 897-908.

34. É. Joó, H. Van Langenhove, M. Šimpraga, K. Steppe, C. Amelynck, N. Schoon, J. F. Müller, and J. Dewulf, Variation in biogenic volatile organic compound emission pattern of Fagus sylvatica L. due to aphid infection, Atmospheric Environment, 2010, 44(2), 227-234.

35. G. Benelli, R. Pavela, K. Cianfaglione, D. U. Nagy, A. Canale, and F. Maggi, Evaluation of two invasive plant invaders in Europe (Solidago canadensis and Solidago gigantea) as possible sources of botanical insecticides, Journal of Pest Science, 2019, 92(2), 805-821.

36. R. M. Keane, and M. J. Crawley, Exotic plant invasions and the enemy release hypothesis, Trends in Ecology and Evolution, 2002, 17(4), 164-170.

37. A. Sunny, S. Diwakar, and G. P. Sharma, Native insects and invasive plants encounters, ArthropodPlant Interactions, 2015, 9(4), 323-331.

38. I. Pereira, P. Severino, A. C. Santos, A. M. Silva, and E. B. Souto, Linalool bioactive properties and potential applicability in drug delivery systems, Colloids and Surfaces B: Biointerfaces, 2018, 171, 566-578. 